\title{
Pulmonary fissures and lobar variations in relation to surgical \&Radiological implications
}

\author{
Hemanth.Kommuru ${ }^{1}$, Sree Lekha $D^{2}$., Hema Priya.J ${ }^{3}$, Swayam Jothi. $S^{4}$. \\ 1,3\&4(Shri Sathya Sai Medical College \& Research Institute., Kancheepuram (dist) Tamil Nadu,India) \\ 2 (Guntur medical college, Guntur Andhra pradesh,India)
}

\begin{abstract}
Lungs are separated into lobes by fissures, with three lobes on the right and two on the left. The fissures facilitate the uniform expansion of the whole lung. The anatomical knowledge of the fissures and the lobes of the lung is important for accurate interpretation of bronchopulmonary segments on X-rays and CT scans. 40 pairs of lungs removed from cadavers were utilized for the study of the pattern of lobulations by careful dissection. Observations were made for the absence or presence of fissures and when present whether it is complete or incomplete. The findings are also confirmed with the help of the X-rays.

On the right side four lungs showed the absence of horizontal fissure, twelve lungs showed incomplete horizontal fissure and in fourteen lung specimens inferior lobe showed an accessory lobe. In seven lungs accessory fissures were seen. On the left side in fourteen specimens extra lobe was present in between the two lobes, in four lungs incomplete oblique fissure was present and in eight lungs accessory fissures were seen.

Anatomical knowledge of the presence of accessory lobes and fissures in the lung may be important for performing lobectomies, surgical resections involving individual segments and to radiologists for accurate interpretation of radiological images
\end{abstract}

Key Words- Lobes; Oblique fissure; Transverse fissure

\section{Introduction:-}

The lungs are pair of essential respiratory organs in the humans. They are separated into lobes by fissures, with three lobes on the right and two on the left. The oblique fissure cuts the vertebral border of both the lungs at the level of 4th or 5th thoracic spine. Traced downwards on the medial surface it ends above the hilum; traced downwards on the costal surface it continues across the diaphragmatic surface and turns upward on to the medial surface to end just below the lower end of the hilum. Rosse and Gaddum-Rosse ${ }^{1}$. Horizontal fissure, seen only in the right lung begins laterally at the oblique fissure and runs almost transversely across the costal surface to the anterior margin and around this margin back to the hilum to separate a wedge-shaped middle lobe from the upper lobe Last ${ }^{2}$. It passes at the level of midaxillary line to the anterior border of the lung at the level of sternal end of 4th costal cartilage Standring ${ }^{3}$. Knowledge of their position is necessary for the appreciation of lobar anatomy and thus for locating the bronchopulmonary segments which is significant both anatomically and clinically. The fissures may be complete, when the lobes remain held together only at the hilum by the bronchi and pulmonary vessels, or they may be incomplete when there are areas of parenchymal fusion between the lobes, or, they may be absent altogether Meenakshi et al. ${ }^{4}$.

1.1 Embryology: During the development, as the lung grows, the spaces that separate individual bronchopulmonary buds become obliterated except along two planes, evident in the fully developed lungs as oblique and horizontal fissures Larsen ${ }^{5}$. Absence or incomplete fissures could be due to the obliteration of these fissures either completely or partially. Accessory fissure could be the result of non-obliteration of spaces which normally are obliterated Meenakshi et al. ${ }^{4}$

\section{Materials and Methods: -}

40 pairs of lungs removed from cadavers were used to study the variations in fissures (complete or incomplete) and lobes (less than the normal number of lobes or for the presence of extra lobes).

\section{Results:-}

On the right side four lungs showed the absence of horizontal fissure and had only two lobes (Fig:1). Twelve lungs showed incomplete horizontal fissure (Fig:2) and in fourteen lung specimens inferior lobe showed an accessory lobe(Fig:3). In seven lungs accessory fissures were seen (Fig:4). On the left side in fourteen specimens extra lobe was present in between the two lobes(Fig:5), in four lungs incomplete oblique fissure was present(Fig:6) and in six lungs below the lingula a separate lobe like partition of the lung was seen (Fig:7). In eight lungs accessory fissures were seen (Fig: 8). In two lungs a separate projection was seen below the lingula (Fig:9). 


\section{Discussion: -}

If the pulmonary development is defective, it will give rise to variations in lobes and fissures of lung Modgil et al. ${ }^{6}$. Absence or incomplete oblique or horizontal fissures could be due to obliteration of these fissures either completely or partially Meenakshi et al. ${ }^{4}$

Medlar $^{7}$ in his examination of 1200 pairs of lungs found that the horizontal fissure was absent in $45.2 \%$ and incomplete in $17.1 \%$ of the right-sided lungs. According to Lukose et $\mathrm{al}^{8}$ incomplete and absence of horizontal fissure was reported in $21 \%$ and $10.5 \%$ respectively. Bergman RA $^{9}$ reported incomplete and absence of horizontal fissure in $67 \%$ and $21 \%$ respectively in right sided lungs. Meenakshi et $\mathrm{al}^{4}$ reported that the horizontal fissure was absent in $16.6 \%$ and was incomplete in $63.3 \%$ of right lungs. According to Prakash ${ }^{10}$ the horizontal fissure on right lung was absent in $7.1 \%$ and incomplete in $50 \%$ of the lung specimens. In our present study the horizontal fissure was absent in $10 \%$ of lungs and incomplete in $30 \%$ of the lung specimens.

Several authors have reported varying percentages of incidence of the incompleteness of the oblique fissure in the right lungs but in our study we never found any variation regarding that fissure. According to Prakash $^{10}$ in right lungs one accessory lobe in the inferior aspect was observed in $27.2 \%$ of the lungs, whereas supernumery fissures which were most common in right lower lobe were detected in $35 \%$ of lung specimens. In the present study in right lungs one accessory lobe in the inferior aspect was observed (35\%) and supernumery fissures were present in $17.5 \%$ of lungs.

Medlar ${ }^{7}$, Lukose ${ }^{8}$ and Bergman $\mathrm{RA}^{9}$ in their examination on the left sided lungs found incomplete oblique fissure in $10.6 \%, 21 \%$ and $30 \%$ respectively. In the present study the incomplete oblique fissure was observed in $10 \%$ of the cases. Sometimes, especially in infants, accessory fissures of varying depths can be seen in abnormal locations of the lung, delimiting anomalous lobes which correspond to the normal bronchopulmonary segments and in a radiological point of view, an accessory fissure is important as it can be mistaken for a lung lesion Rosse $\mathrm{C} \&$ Aldur $\mathrm{MM}{ }^{11}$. In the present study accessory fissures were present in $17.5 \%$ and $20 \%$ in right and left sided lungs respectively.

\section{Figures}
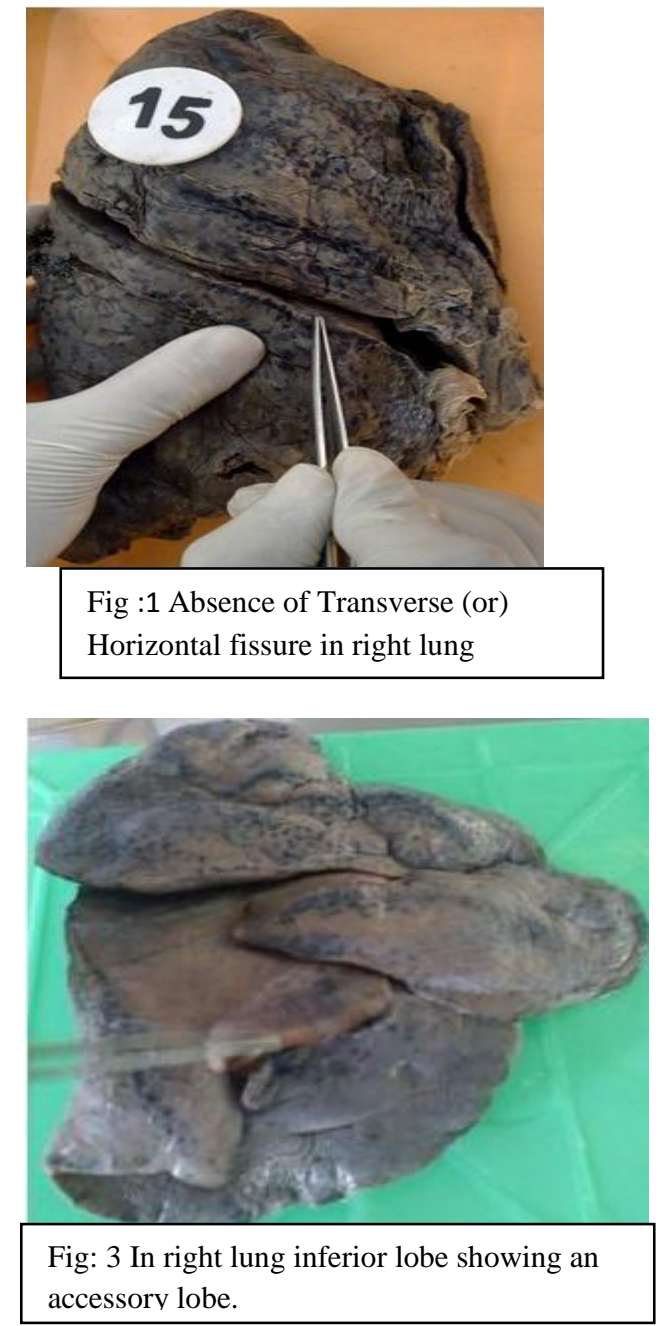
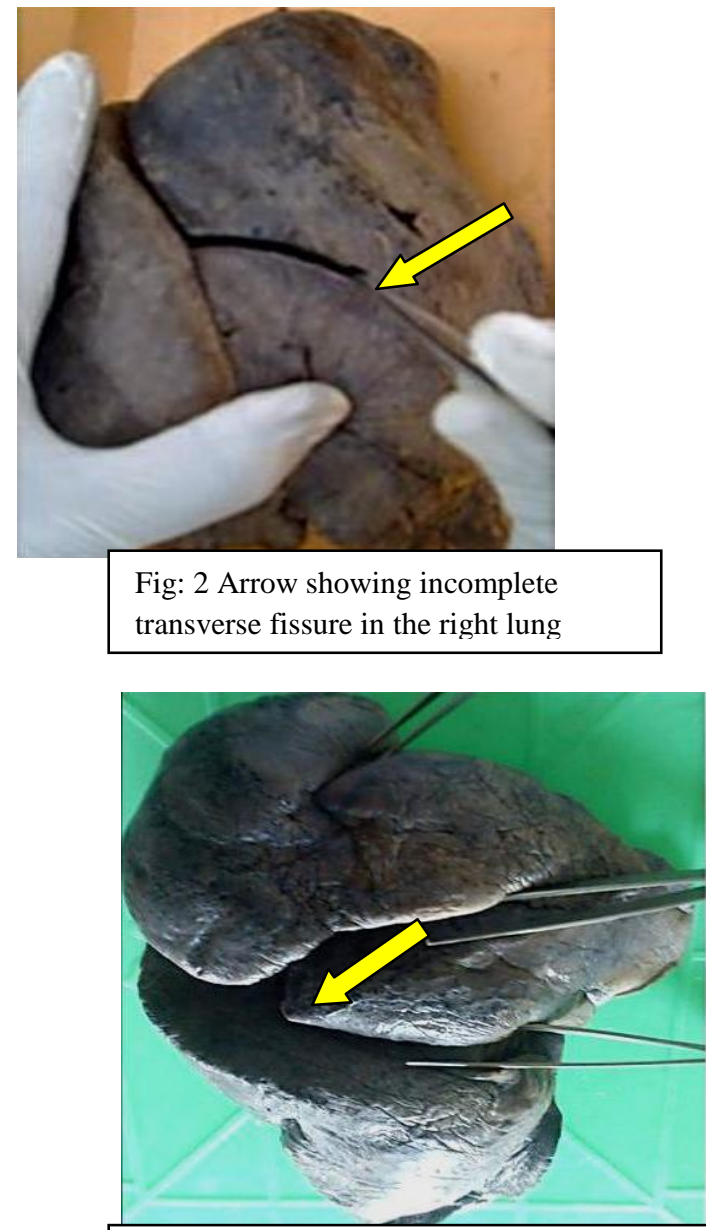

Fig: 4 In right lung inferior lobe showing accessory fissure. 


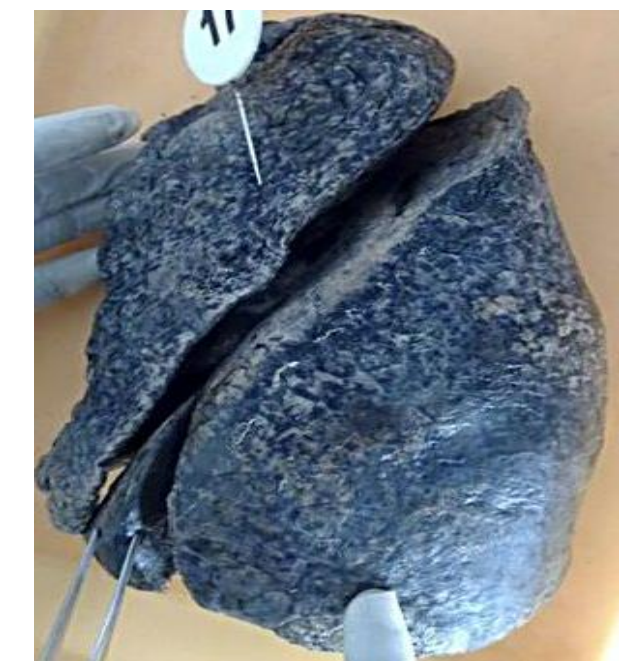

Fig: 5 Extra lobe in between the two lobes in the left lung

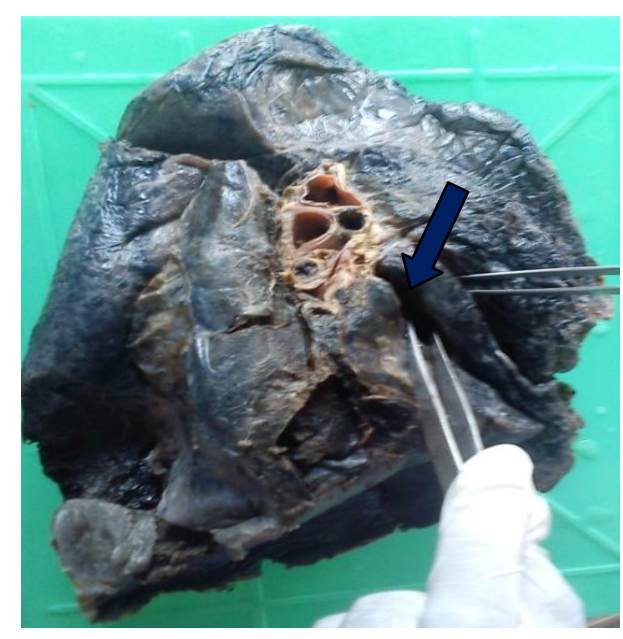

Fig:7 In the left lung accessory fissure was seen

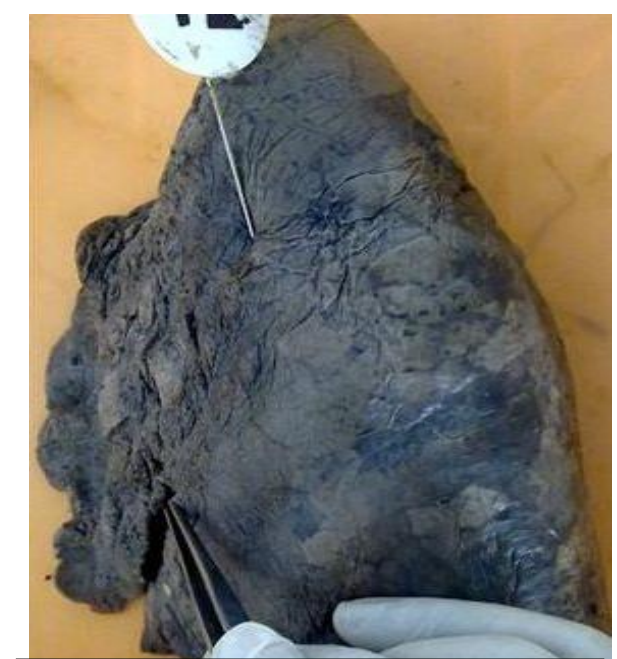

Fig: 6 Incomplete oblique fissure in the left lung

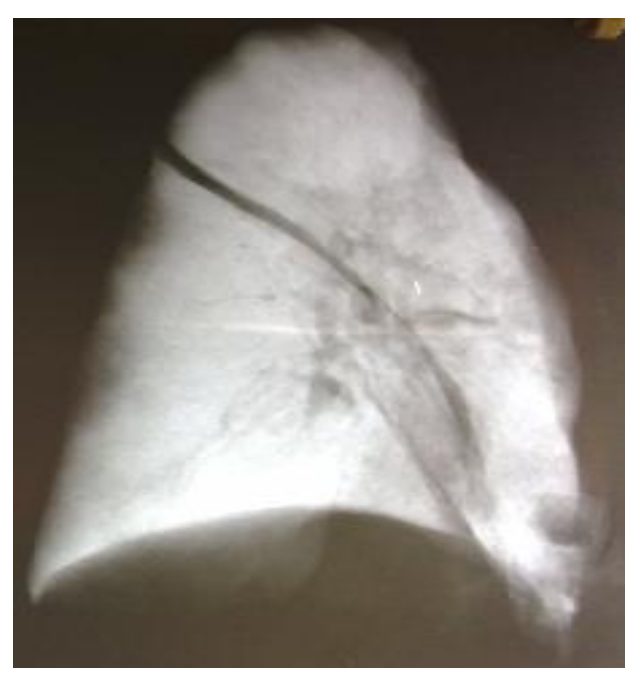

Fig:8 Radiological view of the Fig :7

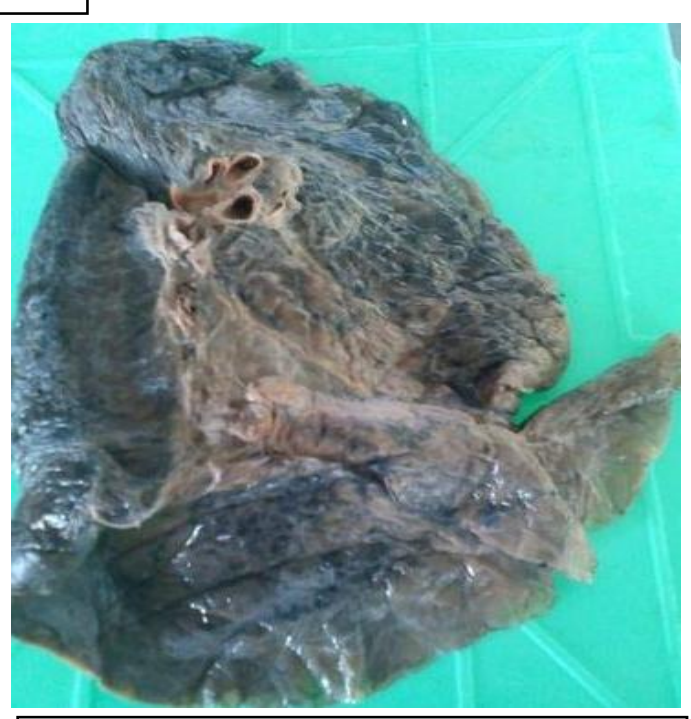

Fig: 9 below the lingula an extra projection in the left lung 


\section{Conclusion:-}

The anatomy of the fissures is used as reliable landmarks in planning the pulmonary resection whereas incomplete fissures may contribute to post-operative air leakage. Incomplete fissures may alter the usual patterns of collapse of the lung seen in with endobronchial lesions and may also give rise to atypical appearance of pleural effusions thus complicating the identification of various pathologic conditions. Pneumonia and carcinoma in a particular lobe is often limited to that lobe alone by the fissures and may spread to adjacent lobes through the incomplete fissures Tarver $\mathrm{RD}^{\mathbf{1 2}}$. The knowledge of anatomy of fissures of lung may help to clarify confusing radiographic findings like extension of fluid into an incomplete major fissure or spread of various diseases through different pathways Dandy WE Jr${ }^{13}$. Considering the clinical and surgical importance of such variations, the anatomical knowledge of variations in the fissures and lobes in the lungs may be important for Pulmonologists, Radiologists, Surgeons and Clinicians.

\section{References:-}

[1] Rosse, C. and P. Gaddum-Rosse, 1997. Hollinsheds Textbook of Anatomy. Lippincott-Raven, Philadelphia, pp: 441-61.

[2] Last, R.J., 2000. Anatomy Applied and Regional. 6th Edn., Churchill Livingstone. New York, pp: 207

[3] Standring, S., 2005. Grays Anatomy. 39th Edn., Churchill Livingstone, New York, pp: 947.

[4] Meenakshi, S., K.Y. Manjunath and V. Balasubramanyam, 2004. Morphological variations of the lung fissuresand lobes. Indian J. Chest Dis. Allied Sci., 46: 179-182.

[5] Larsen, W.J., 1993. Human Embryology. Churchill Livingstone, New York, pp: 111-30.

[6] Modgil, V., S. Das, and R. Suri, 2006. Anomalous lobar pattern of right lung: A case report. Int. J. Morphol., $24: 5-6$.

[7] Medlar, EM., 1947. Variations in interlobar fissures. AJR, 57: 723-725

[8] Lukose, R., P.S. Sunitha, M. Daniel, S.M. Abraham and M.E. Alex et al., 1999. Morphology of the lungs: Variations in the lobes and fissures. Biomedicine, 19: 227-232.

[9] Bergman, R.A., A.K. Afifi and R. Miyauchi, 1999. Variations in peripheral segmentation of right lung and the base of the right and left lungs. Illustrated. Encyclopedia of Human Anatomic Variation

[10] Prakash, Bhardwaj AK, Shashirekha M, Suma HY, Krishna GG, Singh G. Lung morphology: a cadaver study in Indian population. Ital J Anat Embryol. 2010;115(3):235-40

[11] Aldur MM, Denk CC, Celik HH, Tascioglu AB. An accessory fissure in the lower lobe of theright lung. Morphologie 1997; 81 : 5-7.

[12] Tarver RD. How common are incomplete pulmonary fissures, and what is their clinicalsignificance? AJR 1995; $164: 761$

[13] Dandy WE Jr. Incomplete pulmonary interlobar fissure sign. Radiology. 1978; 128: 21-25. 